patient's senses that which was anguish, suffering, and tortnre; whilst, generally, it permits the surgeon to perform his duty with a serenity of thought and action quite unknown to

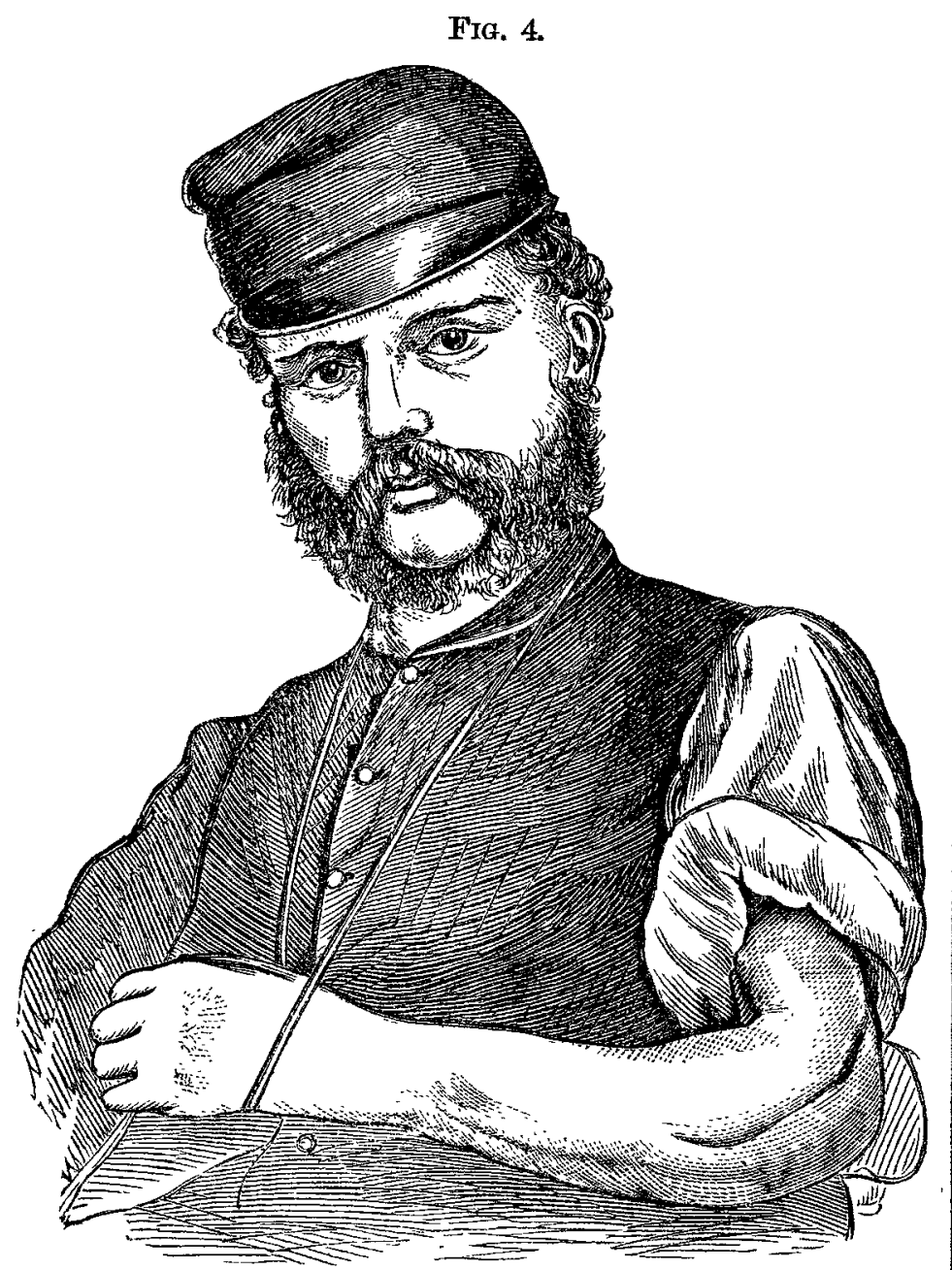

his predecessors. On this subject America again must have the palm of precedence. There sulphuric ether still holds the first place as the anæsthetic agent; whilst with us chloroform, whose influence was first observed and made public by one of our contemporaries, is considered the most useful. Not long ago Dr. Marion Sims, with landable enthusiasm, claimed for metallic stitches the honour of being, in our profession, the greatest discovery of the nineteenth century. Few surgeons of practical experience, however, will endorse this. I see nothing which has transpired in the present century which, in magnitude or importance, can compare in our annals with anæsthesia; and, in my mind, it ranks in value to mankind scarcely less than the results of the labours of Harvey and of Jenner.

We congratulate ourselves that we have been permitted to live in times when man has displayed his mastery over steam and electricity, and with us and our special profession there have been agencies at work whose nsefulness may be said to be literally beyond calculation. I allude to the improved faci lities for education, to our social professional customs, to the medical press, and our own special literature. Our schools have increased in number; our great public hospitals associate, more extensively than ever, education with charity; our handbooks, our works of reference, our means for learning, our appliances for teaching, are beyond compare; and facili. ties for studying anatomy have, by a wise legislation, been placed lawfully within reach. Our Societies and professional gatherings have encouraged and facilitated the diffusion of knowledge : man meets man face to face; thoughts fiash almost simultaneously from brain to brain; and there is no longer a diffeculty with those in places dis:ant from a metropolis to find out even some roundabout way of communicating interesting or useful knowledge to the profession. A surgeon to a Liverpool hospital in the prezent day need not, as Park did in 1782 , address himself to a leading hospital surgeon in London to give currency to his aspirations; nor need the Moreaus of our day keep their originality under the "cold shade" of an academy or a corporation. Besides the facilities for individual and independent publication, there are our quarterly, monthly, and weekly journals to carry knowledge to the ends of the earth. We pride ourselves in this country on the liberty of the press we fondly call it our fourth estate; politically and professionally it may be called the pulse of the public mind; and amongst ourselves in our own time it beats with a healthy vigour, indicative of all those changes for the better which I have endeavoured to sketch, although I fear but feebly, within the limits of a single lecture.

\section{REPORT OF TWO CASES or}

\section{PARTIAL PARALYSIS ()F MUSCLES OF THE LEG ATTENDED WITH TALIPES EQUINUS, IN INFANTS, RESULTING FROM MEASLES.}

\author{
BY HOLMES COOTE, F.R.C.S., \\ SURGRON TO ST. BARTHOLOMEW'S HOSPITAL.
}

MARY M-, aged six years, a healthy-looking child, was brought to the Royal Orthopædic Hospital on Nov. 19th, 1863, with talipes equinus of the right foot. The length of the limb was a quarter of an inch shorter, the circumference of the thickest part of the calf half an inch less, than its fellow; that of the thigh rather more than half an inch. But the temperature was not sensibly below the usual standard. The muscles in front of the leg were wasted, as were also the muscles of the calf; but yet the latter were so far contracted as to hold the heel firmly at a right angle to the leg, producing the deformity which is designated "rectangular talipes equinus."

The history of the case was briefly as follows:-The child had been born healthy. Four years sgo she had an attack of measles, on the subsidence of which the parents noticed that the child "walked lame." They were assured that she would "grow out of it ;" but the condition of lameness has increased year by year.

John G-, aged five years, a healthy.looking boy, was brought to the same hospital on Nov. 19th, 1863, with talipes equinus of the left foot, following an attack of measles. In this case the calf was half an inch less in circumference than that of the sound limb, bat the amount of shortening was very slights The temperature was scarcely altered, but the foot suffered when the cold was severe. The attack of measles had oecarred two years previous. The parents said that they had noticed nothing during its course to lead them to expect this paralytic affection.

I have mentioned these two cases, not because they are rare, but because their nature, progress, and treatment are so little understood. The nature of the case consists in a lesion of the spinal cord or of its membranes during the course of the fever. The progress of the disease will be marked by the increasing disparity between the two limbs. The treatment will consist in close attention to the general health; in attempts to maintain the circulation of the limb by the aid of warmth, frictions, and electricity; and, finally, perhaps in bringing the raised heel to the ground. by means of tenotomy, the use of Scarpa's shoe, and the ployment of irons.

Had the brain and its membranes been the seat of disease, instead of the spinal cord, the child would most probably have died, or, in the event of recovery, have lost control over the voluntary muscles. Its movements would have been spasmodie the heels, perhaps, raised, and the knees bent; but there would have been neither muscular atrophy nor loss of temperature.

We all know that convulsive affections are rare, either an preceding the eruption of measles, or as occurring during its progress ; but the headache, intolerance of light, suffused eyes, somnolence, and agitation when roused, all point to morbic conditions of the nervons centres, which, as in the cases bere related, have led to permanent deformity.

I would mention, in conclusion, that cases of infantile para1 ysis appear at the Orthopædic Hospital in the propartion of from 70 to 80 out of every 1000 cases. The usual exciting causes are difficult dentition, the complications of the eraptive disorders-scarlatina, measles, small.pox, \&c. ; the irritation produced by intestinal worms, \&c. Sensation suffers in a fas less degree than does the power of motion.

Queen Anne-street, May, 1864. 